\title{
Opinion and Expectations of Undergraduate Medical Students on Current Teaching Practices, SMS Medical College, Jaipur
}

\author{
Amita Kashyap ${ }^{1}$, Monika Rathore ${ }^{2}$, Priyanka Kapoor ${ }^{3 *}$, Anshul Gupta ${ }^{3}$ \\ 1Professor and Head, 2Professor, ${ }^{3+}$ Senior Resident, \\ Department of Community Medicine, S.M.S. Medical College, Jaipur, Rajasthan, India.
}

\begin{abstract}
Objective: The study analyzed the opinion of under graduate medical students about present teaching practices, their expectations, their views and suggestions about various aspects of current medical education.

Material and methods: This cross sectional observational study was conducted in the SMS Medical College during November 2014 to January 2015. Four hundred and eighty students of four running semesters participated in the study through structured questionnaire.

Results: Approximately 67\% (316/480) of the students favor change in current duration and timing of teaching hours. Only one third (32\%) students believed that teachers are doing total justice to their job and $12.5 \%$ of students felt that teaching was of poor quality. Twenty percent students are not comfortable with English language. Reason for low attendance was either "teachers don't come for class" $(45 \%)$ or "timings are not suitable" $(43 \%)$. Almost half $(49 \%)$ of students were in favor of teaching with black-board, $36 \%$ for power-point presentation and $15 \%$ prefer combined method. Students observed that around one third teachers make sessions interactive, $70 \%$ used power-point presentation, and Majority of them just read it without explaining. Only 20\% used the concept of "problem based learning". Seventy percent students find sitting arrangements in classroom comfortable but the students on
\end{abstract}

\section{INTRODUCTION}

Abraham Flexner once quoted that Medical education is not just a program for building knowledge and skills in its recipients; it is also an experience which creates attitudes and expectations. ${ }^{1}$ Even minor mistakes can have serious consequences so the standard of medical education should be strictly regulated and regularly updated. ${ }^{2}$ To meet the requirements of such a demanding and diversified professional field, a wealth of cognitive, psychomotor and behavioral skills, and great enthusiasm for the medical profession are a condition sine qua non. ${ }^{3}$ Medical Council of India $(\mathrm{MCl})$ has given many notable recommendations for the improvement of the current system in 'Vision 2015' document. ${ }^{4}$ Medical education is a part of the whole system of education which is in crisis mode today. 5,6 Today, India has the highest number of medical colleges in the world. ${ }^{4}$ There were 381 Medical colleges in the country with annual intake of 50,068 medical students in 2013-14. Inadequate number of doctors could be back benches were unable to see black board $(40 \%)$ and screens $(22 \%)$. More than half students opined that cleanliness in classroom is not up to the mark. Approximately $55 \%$ students did not like the present set up of completing community medicine in $7^{\text {th }}$ semester, they think that it should be continued till 9th semester. Half of students said that field training in community medicine is inadequate.

Key Words: Medical education, Opinion, Students, Teaching methods.

\section{${ }^{*}$ Correspondence to:}

Dr Priyanka Kapoor,

Senior Resident

Department of Community Medicine,

S.M.S. Medical College, Jaipur, Rajasthan, India.

Article History:

Received: 16-07-2016, Revised: 17-08-2016, Accepted: 02-09-2016

\begin{tabular}{|l|c|}
\hline \multicolumn{2}{|c|}{ Access this article online } \\
\hline $\begin{array}{l}\text { Website: } \\
\text { www.jjmrp.com }\end{array}$ & Quick Response code \\
\hline DOl: & \\
10.21276/ijmrp.2016.2.5.028 & \\
\hline
\end{tabular}

compensated to some extent by raising the quality of training of doctors. ${ }^{2}$

Thus the National Knowledge Commission (NKC) formed a working group on medical education to Identify problems and challenges relating to curriculum, teaching, infrastructure, administration and access and recommend changes and means of strengthening and expanding educational opportunities in medical sciences and promote research tradition and raising average standards and creating centers of excellence etc. ${ }^{5}$ Currently course curriculum of medical sciences is prepared by Teaching faculties, politicians and Government officers in education ministry without consulting the students for whom it is made. ${ }^{8}$ It is an important issue to know what students think about present medical education system. Their feedback can help the authorities to find the pitfalls and gaps which need to be focused for corrections. 


\section{OBJECTIVES}

1) The present study is aimed to analyze the perception of medical undergraduates about current teaching practices in SMS medical college, Jaipur.

2) To find expectations and suggestions of students for improvement.

\section{MATERIAL AND METHODS}

This cross sectional observational study was conducted in the SMS Medical College during November 2014 to January 2015. Institutional Ethics committee permission was taken prior to the study. A structured validated questionnaire was prepared with help of a panel of five experienced faculties of SMS Medical College. The questionnaire consists of 35 questions including both open and closed ended questions on positive, negative aspects of current teaching practices and suggestions for improvement. Students from all running batches were included in the study except first semester. All students were asked to participate in the study and explained that their anonymity would be maintained, 480 students gave consent. The Questionnaire was given during class time to fill. Response rates were $100 \%$. They were encouraged to give suggestions or remarks. The quality and teaching practices in the last class attended by students was considered for answering the quality related questions. The completed questionnaires was collected and statistically analyzed to compute the results using Microsoft excel and primer software.

\section{RESULTS}

There were $289(60.2 \%)$ males and 191 (39.8\%) females. 201(41.88\%) students were from rural and 279 (58.12\%) were from urban background. Average age of students was 21.23 years (+/-1.89) with a range of 17 to 26 years. Overall 80\% (385/480) students are comfortable with teaching in English language. Language problem was more among students from rural background $(32.84 \%, 66 / 201)$ than urban $(10.4 \%, 29 / 279)$ $(p=0.00)$ and by students from socioeconomic class IV $(42.1 \%$, 8/19). ( $p=0.008)$. (Table 1)

Currently theory classes are scheduled from 8 AM to 4 PM intermittently. Almost $70 \%$ (316/480) of the students want to change the timing of theory classes. Majority of them were in favor of early morning theory classes i.e. from $7 \mathrm{am}$ to $11 \mathrm{am}$, that too, in one inning. They feel that afternoon theory classes should be avoided because they feel sleepy and less attentive in theory lectures at this time. They preferred $11 \mathrm{am}$ to $2 \mathrm{pm}$ for Clinical posting and suggested that three hours of these bedside clinics should be equally divided for self-study, skill training given by resident and senior faculty. They also suggested 2 hours evening Ward posting from 5 to $7 \mathrm{pm}$ under guidance of senior resident or at least third year resident.

The most commonly stated reasons for not attending the classes were unsuitable timing of classes $(43.3 \%, 208 / 480)$, previous experience that Teacher didn't come in earlier classes $(45 \%$, 219/480). (Table 2)

Table 1: Association of Language problem with socioeconomic class and residence

\begin{tabular}{|c|c|}
\hline Socioeconomic class & Language problem \\
\hline Class $1 \quad(n=89)$ & $12(13.48 \%)$ \\
\hline Class $2(n=294)$ & $53(18.03 \%)$ \\
\hline Class $3(n=78)$ & $22(28.2 \%)$ \\
\hline Class $4(n=19)$ & $8(42.1 \%)$ \\
\hline \multirow[t]{2}{*}{ Grand Total $(n=480)$} & $95(19.79 \%)$ \\
\hline & Chi-square $=12.245$ with 3 degrees of freedom; $P=0.008$ \\
\hline \multicolumn{2}{|l|}{ Residence } \\
\hline Rural (n=201) & $66(32.84 \%)$ \\
\hline Urban $(n=279)$ & $29(10.39 \%)$ \\
\hline \multirow[t]{2}{*}{ Grand Total $(n=480)$} & 95 \\
\hline & Chi-square $=35.665$ with 1 degree of freedom; $P=0.000$ \\
\hline
\end{tabular}

Table 2: Reasons given by students for not attending classes

\begin{tabular}{llcc}
\hline S.N. & Reason for not attending classes & No of students $(\mathbf{n = 4 8 0})$ & $\%$ \\
\hline 1. & Class timing are not suitable & 208 & 43.3 \\
2. & Easy subjects can be prepared without attending classes & 97 & 20.2 \\
3. & Teachers are not delivering much in class & 164 & 34.2 \\
4. & Stop going for those classes where teacher do not take the class & 219 & 45.6 \\
5. & Need to go home on festivals or other occasions & 136 & 28.3 \\
6. & There is no hands on training (skill transfer) in practical classes & 134 & 27.9 \\
& (all theory again) & & \\
\hline
\end{tabular}

Table 3: Student's perception of Quality of teaching

\begin{tabular}{llcc}
\hline S. N. & Quality of teaching* & $\mathrm{n}=\mathbf{4 8 0}(\%)$ & $\mathbf{9 5 \%}$ confidence interval \\
\hline $\mathbf{1}$ & Good & $156(32.5 \%)$ & $28.3-36.7$ \\
$\mathbf{2}$ & Satisfactory & $153(31.88 \%)$ & $27.7-36.1$ \\
$\mathbf{3}$ & Dissatisfactory & $111(23.12 \%)$ & $19.4-27$ \\
$\mathbf{4}$ & Poor & $60(12.5 \%)$ & $9.5-15.5$ \\
\hline
\end{tabular}


Table no 4: Teaching practices of Medical Teachers

\begin{tabular}{llcc}
\hline S.N. & Mode of Teaching/ Teaching tools & Positive Responses & 95\% confidence interval \\
\hline 1. & Lecture with help of power point & $336(70 \%)$ & $65.8-74.2$ \\
2. & Just read power point & $245(51.04 \%)$ & $46.44-55.64$ \\
3. & Use of mike & $221(46.04 \%)$ & $41.44-46.086$ \\
4. & Try to make sessions interactive & $135(28.12 \%)$ & $23.92-32.32$ \\
$\mathbf{5 .}$ & Use of problem based learning approach & $96(20 \%)$ & $16.4-23.6$ \\
\hline
\end{tabular}

Only $32 \%$ Students feel that Teachers did full justification to their jobs and delivered good quality teaching in the previous class they attended, while $12.5 \%$ of students perceive that teaching was of poor quality. (Table 3) Students observed that around one third teachers made sessions interactive, $70 \%$ used power-point presentation, $51 \%$ teachers just read it and only $20 \%$ used the concept of "problem based learning" (Table 4).

Seventy percent students find sitting arrangements in classroom comfortable but the students on back benches were unable to see black board $(40 \%)$ and screens (22\%). More than half students opined that cleanliness in classroom is not up to the mark.

\section{(Table 5)}

Regarding teaching Aids, 49.17\% (236/480) students preferred blackboard, $36.04 \%$ (173/480) power point presentation and $14.79 \%$ (71/480) preferred combined method. Majority of students $(91.25 \%, 438 / 480)$ try to seek mentor in their teacher while very few $(8.75 \%, 42 / 480)$ state that the role of teacher should be limited to teaching only and should not interfere in their personal life. As shown in Table 6, around 54\% (258/480) of students revealed that they are not happy with final exams of Community Medicine in VII semester as during I \& III semester their priority is
Anatomy, physiology and during III to $\mathrm{V}$ semester, priority is Pharmacology and Pathology thus they do not pay much attention to Community Medicine. In addition, without studying Medicine, Gynecology and Pediatrics, they find preventive and other aspects of public health very difficult to understand. Hence it should be shifted to IX semester.

\section{Expectations of students}

Most of the students expect teachers to be friendly, cooperative, motivating and experienced. Classes should be interactive with audiovisual aid and improved projectors. (Table 7) There are some areas which need improvements as shown in table 8.

\section{Suggestions (Table-9)}

1) Teaching should be more interactive, illustrative,

2) More clinical, and practical and MCQ based.

3) Afternoon theory classes should be avoided,

4) Projectors and mikes should be functional,

5) More research projects

6) Formation of a college portal to share experience/ complains,

7) Monthly sessions with principal to discuss problems, more field visits.

8) Teaching in Hindi also, along with English.

Table no 5: Student's perception for quality of class rooms

\begin{tabular}{|c|c|c|c|}
\hline S.N. & Classroom arrangement & & No of students (\%) \\
\hline \multirow[t]{3}{*}{1} & Sitting arrangement is comfortable & Not at all & $55(11.46 \%)$ \\
\hline & & Somewhat comfortable & $337(70.2 \%)$ \\
\hline & & Totally comfortable & $88(18.34 \%)$ \\
\hline \multirow[t]{2}{*}{2} & Blackboard is visible from all seats & Yes & $289(60.21 \%)$ \\
\hline & & No & $191(39.79 \%)$ \\
\hline \multirow[t]{2}{*}{3} & Screen is visible from all seats & Yes & $374(77.92 \%)$ \\
\hline & & No & $106(22.08 \%)$ \\
\hline \multirow[t]{4}{*}{4} & Noise in surroundings & No noise & $84(17.5 \%)$ \\
\hline & & Very little disturbance & $232(48.33 \%)$ \\
\hline & & Moderate disturbance & $138(28.75 \%)$ \\
\hline & & Much disturbance & $26(5.42 \%)$ \\
\hline \multirow[t]{3}{*}{5} & Environment & Conducive of learning & $110(22.92 \%)$ \\
\hline & & Somewhat conducive & $334(69.58 \%)$ \\
\hline & & Not at all conducive & $36(7.5 \%)$ \\
\hline \multirow[t]{5}{*}{6} & Cleanliness in classroom & Very good & $11(2.3 \%)$ \\
\hline & & Good & $131(27.3 \%)$ \\
\hline & & Just ok & $263(54.8 \%)$ \\
\hline & & Poor & $65(13.5 \%)$ \\
\hline & & Very poor & $10(2.1 \%)$ \\
\hline
\end{tabular}

Table 6: Perception regarding Community medicine teaching

\begin{tabular}{llc}
\hline Community medicine teaching & Responses of students $(\mathbf{n}=\mathbf{4 8 0})$ \\
\hline 1. & Present set of community medicine teaching & \\
& Present setup of completing in $7^{\text {th }}$ semester is good & $222(46.25 \%)$ \\
& Should be taken up with clinical subjects till $9^{\text {th }}$ semester & $258(53.75 \%)$ \\
2. & Quality of field training & \\
Optimal & $224(46.7 \%)$ \\
Inadequate & $236(49.2 \%)$ \\
$\quad$ Not at all & $20(4.1 \%)$ \\
\hline
\end{tabular}


Table 7: Expectations of students regarding teaching

\begin{tabular}{clc}
\hline Expectations of students from teachers & Responses of students (n=480) \\
\hline 1. & Friendly & $457(95.2 \%)$ \\
2. & Experienced & $403(84 \%)$ \\
3. & Cooperative & $370(77.1 \%)$ \\
4. & Motivating teachers & $401(83.54 \%)$ \\
5. & Use of power point & $336(70 \%)$ \\
6. & Use of projectors & $321(66.87 \%)$ \\
7. & Interactive & $432(90 \%)$ \\
\hline & & \\
\hline Area needs improvement & Table 8: Area needs improvement & $312(65 \%)$ \\
\hline 1. & Non interactive teachers & $336(70 \%)$ \\
2. & Afternoon theory classes needs to be shifted in morning hours, & $192(40 \%)$ \\
3. & Final year classes in pre final, & $252(52.5 \%)$ \\
4. & Just reading of power point without explanation , & $166(34.58 \%)$ \\
5. & Nonfunctioning projectors, & $269(56 \%)$ \\
6. & Teaching not as per the pattern of pre-pg exam, & $390(81.25 \%)$ \\
7. & Less clinics, less practical, & $82(17.1 \%)$ \\
8. & No group discussions, & $332(69.16 \%)$ \\
9. & Timings not suitable, & $274(57.1 \%)$ \\
10. & Classes too much, whole day busy in classes, sleepy classes.
\end{tabular}

Table 9: Suggestions given by students

\begin{tabular}{clc}
\hline Suggestions by students & Responses of students (n=480) \\
\hline 1. & Teaching should be more interactive & $423(88.13 \%)$ \\
2. & More clinical and more practical, improve bedside clinics & $394(82.1 \%)$ \\
3. & Illustrative teaching & $259(55.96 \%)$ \\
4. & MCQs based teaching (pre PG exam based) & $297(61.88 \%)$ \\
5. & More focus on research projects & $82(17.1 \%)$ \\
6. & Avoid afternoon theory classes & $348(72.5 \%)$ \\
7. & Exclude final year subjects from pre finals & $192(40 \%)$ \\
8. & Improve projectors and mikes & $334(69.59 \%)$ \\
9. & More group discussion, Quiz & $58(12.08 \%)$ \\
10. & Start personality and English speaking classes & $24(5 \%)$ \\
11. & Start teaching any Major clinical subject for 3 month after 2nd year & $35(7.29 \%)$ \\
12. & Prohibition of entry of non SMS students in library & $87(18.13 \%)$ \\
13. & Compulsory one month night postings per year even for I \& II MBBS students & $10(2.08 \%)$ \\
14. & A college portal should be formed to share experience/ complains, or sessions with & $48(10 \%)$ \\
& principal to discuss problems & \\
15. & Replace experimental physiology and pharmacology with clinics & $5(1.04 \%)$ \\
16. & More field visits & $192(40 \%)$ \\
17. & Teaching should be in Hindi also along with English & $341(71.04 \%)$ \\
18. & No compulsion for attendance (relaxation for attendance) & $441(91.87 \%)$ \\
\hline
\end{tabular}

\section{DISCUSSION}

In our study $49.2 \%$ (236) of the students preferred for black board teaching method while $36.04 \%$ (173) preferred for power point and $14.8 \%$ (71) were in favor of combined black board and power point method. Similar findings were got according to the study done by Shreemanta Kumar Dash et al ${ }^{9}$ on MBBS students of KIMS, Bhubaneswar, $82.83 \%(n=326)$ of the participants agreed that black board teaching as the better mode of teaching, so also $55.87 \%(n=324)$ agreed that audio visual aids as a useful mode of teaching and only $51.85 \%(n=324)$ of them agreed to the point that the teaching faculties are well versed with the rational use of audio visual aids as effective tool for teaching. At the same time participants suggested that the teaching should be done by both black board and audio visual aids which correlates with the study done by Kaushik Bhowmick et al ${ }^{10}$ which tells that $8 \%$ students preferred projector, $30 \%$ preferred black board, $62 \%$ preferred combined black board and ppt. Banerjee et al ${ }^{8}$ concluded in their study that according to the students LCD slide was best mode of teaching followed by chalk and black board method.

Reason for not attending the classes according to the students was mostly in $45 \%$ cases that they have to come back as teachers didn't come. Or timings are not suitable according to $43 \%$ students. While a study done by Shreemanta Kumar Dash ${ }^{9}$ showed that $55.24 \%(n=315)$ of the participants did not agree to the point that class timing as a factor for absence of students from the class rooms, asked about their attitude $44.80 \% \quad(n=308)$ of them disagreed that careless attitude as a reason for absence of students from classes. Reason for absence of students from the classes, the participants pointed out that teaching method of faculties as a major factor. Replying to the questions about the duration of teaching hours, $56.10 \% \quad(n=328)$ of the total participants in study of Dash et al ${ }^{9}$ agreed that the number of practical classes should be more than the theory classes. 


\section{CONCLUSION}

The study hereby concluded that students preferred Interactive and problem based learning rather than just reading power point presentations in the class. They believed that teachers are not doing total justice to their job. Irregularity of teacher and unsuitable class timings leads to absence of students in classes. Majority were comfortable with English language still they prefer combination of Hindi along with English. Students were dissatisfied with cleanliness of classrooms, visibility of black board and screen from back benches, current duration \& timing of teaching hours, afternoon theory classes, and field training of community medicine. More than a half of the students were in favor of continuing community medicine teaching till 9th semester.

\section{REFERENCES}

1. Satendra Singh, Savita Singh, Shikha Gautam. Teaching styles and approaches: medical student's perceptions of animationbased lectures as a pedagogical innovation. Pak J Physiol. 2009;5(1):16-9

2. Aggarwal S, Sharma V. The problems of medical education in a developing economy: The case of India. Ann Trop Med Public Health. 2012;5:627-9

3. Lukas Peter Mileder. Are medical schools hesitant to teach undergraduate students teaching skills? A medical student's critical View. Med Educ Online 2013, 18: 22997 http://dx.doi.org/10.3402/meo.v18i0.22997

[Accessed on 2015 Sept 16]

4. Vision 2015, Medical Council of India. March 2011 available at http://www.mciindia.org/tools/announcement/MCl_booklet.pdf [Accessed on 2015 Sept 15]

5. Report of The Working Group On Medical Education [Accessed on 2015 Sept 15] [Available at

http://knowledgecommissionarchive.nic.in/downloads/documents/ wg_med.pdf]

6. N. Ananthakrishnan. Medical education in India: Is it still possible to reverse the downhill trend? The National Medical Journal Of India.2010;23(3):156-160.
7. Annual Report 2013-2014. Medical Council of India. Available from: http://www.mciindia.org/AboutMCl/AnnualReports.aspx. [Accessed on 2015 Sept 4].

8. Indrajit Banerjee, Akhilesh Chandra Jauhari, Ajay Chandra Johorey, Sudesh Gyawali, Archana Saha. Student's Accreditation of integrated Medical Education in Nepal. Asian Journal of Medical Sciences.2011;2(1): 49-52

9. Shreemanta Kumar Dash, Shubhransu Patro, Basanta Kumar Behera, Teaching Methods and Its Efficacy : An Evaluation by the Students , J Indian Acad Forensic Med. October-December 2013;35(4): 322- 323

10. Kaushik Bhowmick, Mousumi Mukhopadhyay, Sandip Chakraborty, Pradyut K. Sen, Indranil Chakraborty. Assessment of perception of first professional MBBS students in India about a teaching learning activity in Biochemistry. South East Asian Journal of Medical Education. $2009 ; 3(2)$ : 27-34 available at https://www.researchgate.net/publication/265029196_Assessment _of_perception_of_first_professional_MBBS_students_in_India_a bout_a_teaching_learning_activity_in_Biochemistry [Accessed on 2015 Sept 6]

\section{Source of Support: Nil. Conflict of Interest: None Declared.}

Copyright: (c) the author(s) and publisher. IJMRP is an official publication of Ibn Sina Academy of Medieval Medicine \& Sciences, registered in 2001 under Indian Trusts Act, 1882.

This is an open access article distributed under the terms of the Creative Commons Attribution Non-commercial License, which permits unrestricted non-commercial use, distribution, and reproduction in any medium, provided the original work is properly cited.

Cite this article as: Amita Kashyap, Monika Rathore, Priyanka Kapoor, Anshul Gupta. Opinion and Expectations of Undergraduate Medical Students on Current Teaching Practices, SMS Medical College, Jaipur. Int J Med Res Prof. 2016; 2(5):14145. 